\title{
OPEN
}

\section{Author Correction: Investigating the relationship between district- level socioeconomic status and individual obesity in Taiwanese adolescents: A large-scale cross- sectional analysis}

\section{Ying-Lien $\mathrm{Ni} \oplus$, Jen-Ho Chang \& Lung Hung Chen}

Correction to: Scientific Reports https://doi.org/10.1038/s41598-019-39167-5, published online 27 February 2019

In Figure 3, the full district names are missing. The correct Figure 3 appears below as Figure 1.

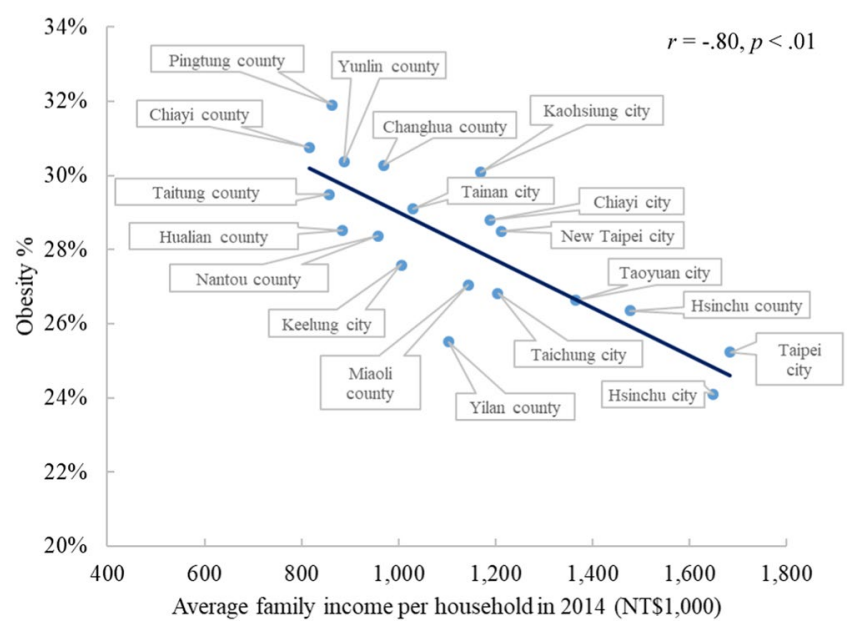

Figure 1.

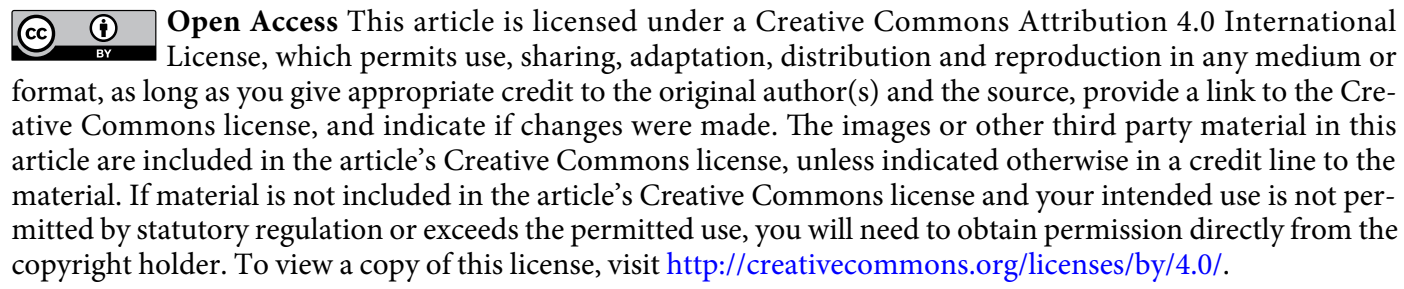

(C) The Author(s) 2020 